\title{
Pharmacokinetic drug-drug interaction study between clindamycin and cyclosporin in rabbits
}

Issam Mohammed Abushammala ${ }^{1 *}$, Lama Attef El Gussein ${ }^{1}$, Badea Elzaman Zomlot ${ }^{1}$, Kamal Fakher Abushammalleh ${ }^{1}$, Mohammed Mahmoud Taha², Mohammed Yousef Miqdad ${ }^{3}$

${ }^{1}$ Department of Pharmaceutics and Industrial Pharmacy, Faculty of Pharmacy, Al Azhar University Gaza, Gaza, Palestine.

${ }^{2}$ Department of Pharmacology, Faculty of Pharmacy, Al Azhar University Gaza, Gaza, Palestine.

${ }^{3}$ College of Dentistry, Al Azhar University Gaza, Gaza, Palestine.

\begin{tabular}{|c|}
\hline ARTICLE INFO \\
\hline $\begin{array}{l}\text { Received on: 01/09/2019 } \\
\text { Accepted on: } 21 / 11 / 2019 \\
\text { Available online: 05/02/2020 }\end{array}$ \\
\hline $\begin{array}{l}\text { Key words: } \\
\text { Cyclosporine, } \\
\text { clindamycin, drug interaction, } \\
\text { pharmacokinetic, CYP3A4. }\end{array}$ \\
\hline
\end{tabular}

\section{INTRODUCTION}

Cyclosporine (CSA) is an immunosuppressant drug with narrow therapeutic index, extracted from fungus Tolypocladium inflatum (Borel 2002; Yang et al., 2018). It works by reducing the function of T-lymphocytes through blocking the phosphatase activity of calcineurin that leads to decrease the T-cell inflammatory cytokines (Matsuda and Koyasu, 2000). CSA is widely used as the first line therapy in prophylaxis and treatment of organ transplant rejection (Azzi et al., 2013), rheumatoid arthritis, psoriasis, and other autoimmune diseases (Faulds et al., 1993). Moreover, CSA is a substrate of CYP3A4. Modulation of CYP3A4 activity can

\footnotetext{
${ }^{*}$ Corresponding Author

Issam Mohammed Abushammala, Department of Pharmaceutics and Industrial Pharmacy, Faculty of Pharmacy, Al-Azhar University, Gaza,Palestine.E-mail: issam.abushammala@uv.es
}

alter PK of CSA as asequence (Larry 2008; Kronbach et al., 1988). The hepatic microsomal cytochrome P450 (CYP450) superfamily includes enzymes that are responsible for the metabolism of many chemical substances (Estabrook, 2003; Kelly and Kahan, 2002). Consequently, the modification of CYP450 enzyme activity can alter the biological activity of xenobiotic substrates via drug-drug interaction (DDI) (Rendic and Di Carlo, 1997). DDI is a specific term used when the efficacy or toxicity of a drug is modified by another administered drug, which may be beneficial or harmful. In last decades, safety and efficacy of DDI have been widely evaluated. Harmful effects; as they are remarkable through (10\%-20\%) of adverse to be hospitalized (Şimşek et al., 2019). Accordingly, sustained and clinically significant DDIs can occur during long-term therapy with CsA when co-administered with other drugs having CYP3A4 inducing or inhibitory effect, resulting in graft rejection or renal dysfunction (Campana et al., 1996). Clindamycin (CLN) is a lincosamide antibiotic that can be used against Gram-positive aerobic bacteria as well as some antiprotozoal actions (Dhawan 
et al., 1982). CLN induces CYP3A4 activity, suggesting a possible DDI between CSA and CLN when those drugs are concomitantly administered. There are limited data about the influence of CLN on CYP3A4 activity. The effect of CLN on CYP3A4 transcription in human hepatocytes and intestinal cells was moderately activated in HepG2 cells but in DPX-2 cells, CYP3A4, mRNA, and protein expression were weakly enhanced through the activation of Pregnane X receptor (PXR) (Yasuda et al., 2008). Suspected interaction were reported when CLN was added to CSA therapy, where serum CSA concentrations reduced continuously as the daily dose of CLN was increased. Interestingly, after CLN treatment was stopped, the dose of CSA was reduced to the initial one before starting antibiotic treatment (Thurnheer et al., 1999). In another study, a novel interaction between tacrolimus and CLN was reported in a renal transplant recipient with Pneumocystis jirovecii pneumonia, where the co-administration of CLN and tacrolimus led to a significant decrease in tacrolimus plasma level (Jouret et al., 2010). Moreover, Wynalda et al. (2003) found that, the incubation of CLN $(100 \mu \mathrm{M})$ with human liver and gut microsomes inhibited $26 \%$ of CYP3A4 activity (Wynalda, 2003). This study aims to figure out the PK changes of CSA upon coadminestering of both CLN and CSA in male rabbits.

\section{MATERIALS AND METHODS}

\section{Chemicals}

Cyclosporine soft capsule (100 mg, Sandimmun Neoral ${ }^{\circledR}$, Novartis, Basel, Switzerland) was gifted from the Ministry of Health, Gaza-Palestine. CSA content from three soft gelatin capsules was diluted with $30 \mathrm{ml}$ normal saline. $3.5 \mathrm{ml}$ were given daily for each rabbit. CLN capsule (300 mg, Dalacin $\mathrm{C}^{\circledR}$, Pfizer, New York, USA) was bought from a private pharmacy (Gaza, Palestine). Capsule contents were transferred and suspended in $16 \mathrm{ml}$ of normal saline and then $1.5 \mathrm{ml}$ was administered for each rabbit daily.

\section{Study design}

Twelve healthy male rabbits (Weighted between 3.2 and $-3.4 \mathrm{~kg}$ ) were enrolled in this research and randomly selected and divided to two groups: Control and test groups (six for each). The study was approved by the Experimental Animal Care Center, Faculty of Pharmacy, Al-Azhar University, Gaza, Palestine. The rabbits were maintained under the regulations of the "Guide for the Care and Use of Laboratory Animals." The rabbits were maintained under standard laboratory conditions of a 12-hour light/dark cycle at $25^{\circ} \mathrm{C} \pm 2{ }^{\circ} \mathrm{C}$ and given pellet diet with free access to water (ad libitum) and fasted overnight prior to the experiments. Each rabbit of the control group received a single oral dose $(10 \mathrm{mg} / \mathrm{kg} /$ day $)$ of CSA solution prepared in normal saline daily, whereas the rabbits of the test group were treated with similar dose of CSA along with an oral dose of CLN ( $8 \mathrm{mg} / \mathrm{kg} /$ day) in normal saline. Doses were given using of a syringe linked to a mouth gavage that was placed in rabbit mouth's corner and the dose was step-wised to prevent choking.

\section{Blood sampling}

Fifteen minutes before starting the practical part and in a restraining box the rabbits were put. Hair around ear was removed and lidocaine $4 \%$ as local anesthetic was applied to avoid rabbits jerking due to venepuncture. On the seventh day after receiving the last dose, blood samples $(2 \mathrm{ml})$ were collected using a small needle (23 gauge) linked to the marginal ear vein (Parasuraman et al., 2010), into heparinized vacutainer tubes at $0.0,0.5,1.0,1.5,2.0,3.0,6.0,12$, and 24 hours. The samples were kept and adjusted at $\left(2^{\circ} \mathrm{C}-8^{\circ} \mathrm{C}\right)$ (whole blood sample is stable for up to 3 days; Shenzhen New Industries Biomedical Engineering Co., Ltd., China).

\section{Analysis of blood samples}

Adjusted amount of reagent as above was added to each sample, mixed together, and put at the vortex mixer for 2 minutes $(2,000 \mathrm{rpm})$. All samples were tested when placed on board of the Maglumi system. The analysis was performed by Maglumi CSA (Cyclosporine detection kit, 130207001M) Maglumi 800 analyzer based on chemiluminescent immunoassay (CLIA) (Shenzhen New Industries Biomedical Engineering Co., Ltd and Snibe. The results for CSA concentrations were given automatically for each sample in $\mathrm{ng} / \mathrm{ml}$ by applying of a calibration curve that is calculated using two-point calibration curve method. The MAGLUMI CSA (CLIA) Kit is an in vitro competitive, and non-enzyme involved flash chemiluminescence immunoassay for the rapid quantitative determination of CsA concentrations in whole blood samples with the Maglumi 800, fully-auto chemiluminescence immunoassay analyzer. Chemiluminescent Immunoassay (CLIA) system is the combination of chemiluminescence determination technology and immunoreaction technology, which possess high sensitivity and specificity.

\section{Determination of pharmacokinetic parameters}

The PK parameters $\left(C_{\max }\right),\left(t_{\max }\right)$, the area under the blood concentration-time curve from 0 hour to last measurable concentration $\left(\mathrm{AUC}_{0-t}\right)$, and the area under the blood concentration-time curve from 0 hour to infinity $\left(\mathrm{AUC}_{0-\infty}\right)$ were calculated in both groups at the mentioned intervals. $C_{\max }$ and $t_{\max }$ were calculated from blood concentration versus time curves, while $\mathrm{AUC}_{0-t}$ was calculated by the linear trapezoidal rule meanwhile, $\mathrm{AUC}_{0-\infty}$ was calculated by summing the area of $\mathrm{AUC}_{0-i}$ and $\mathrm{AUC}_{0-\infty}$, using the equation ${ }^{\text {ref }} \mathrm{AUC}_{0-\infty}=\mathrm{AUC}_{0-t}+C_{t} / K_{\mathrm{e}}$, where " $C_{\mathrm{t}}$ " defined as the last measured serum/blood concentration at time $t$, and $K_{\mathrm{e}}$ is the elimination constant. $K_{\mathrm{e}}$ was calculated using least square regression of plasma/blood concentration-time data points lying in the terminal region using semi-logarithmic dependence that corresponds to first-order kinetic. The $t_{1 / 2}$ was calculated from the equation $\left(K_{\mathrm{e}}=0.693 / t_{1 / 2}\right)$. PK analyses were run using "model independent method (Non-Compartmental Approach" WinNonlin Professional Software Version 6.3, Pharsight Corporation, Cary, NC) and (GraphPad Prism versión 4.00; San Diego, CA).

\section{Statistical analysis}

The data is shown in the term of mean with standard deviation (SD) for each time point in each group. Differences in PK parameters of CSA between the control and test groups were assessed by independent (unpaired) $t$-test, using general linear model procedures. Statistical analyses were achieved using SPSS (Version 16) consistent with significance criteria $(p<0.05)$. 


\section{RESULTS AND DISCUSSION}

Mean blood concentrations-time profile of CSA plot for both groups is given in (Fig. 1). The mean of $C_{\max }$ in control group was $244.7 \pm 115.87 \mathrm{ng} / \mathrm{ml}$, while in test group was $242.90 \pm 104.45 \mathrm{ng} / \mathrm{ml}, p$-value $=0.968$. Time to reach the maximum blood concentration $\left(t_{\max }\right)$ of CSA in control group was $1.75 \pm 0.76$ hours. In test group, $t_{\max }$ was slightly decreased to $1.25 \pm 0.42$ hours which was not significant $(p$-value $=0.314)$. The results of PK parameters are shown in Table 1. The differences in the mean of PK parameters of CSA estimated for the two groups were statistically insignificant, $p>0.05$. Regarding $\mathrm{AUC}_{0-24}$ and $\mathrm{AUC}_{0-\infty}$, the means were 2,057.8 \pm 778.6 and 3,492.9 $\pm 1,449 \mathrm{ng}$. hour $/ \mathrm{ml}$ in the control group and were 2,948.0 $\pm 1,321.44$ and 4,605.4 \pm 2205.20 ng.hour/ml in the test group, respectively. Regarding $t_{1 / 2}$, we found that, the mean was $19.73 \pm 14.01$ versus $17.40 \pm 5.54$ hour, $(p=0.574)$ in control and test groups, respectively. Moreover, the means of $K_{\mathrm{e}}$ were $0.0519 \pm 0.03$ versus $0.0439 \pm 0.01$ hour $^{-1}$, $(p=0.483)$ in control and test group, respectively.

CYP450 enzymes, plays a vital role in DDI-s due to their critical function in drug metabolism. In addition, the importance of the CYP450 system for drug interactions depends on the fact that the activity of CYP enzymes can be inhibited or induced by certain drugs or exogenous substances leading to an alteration of the predicted plasma level of the affected drug. CYP3A and CYP2D6 are responsible for more than 50\% of known drug metabolism, therefore, drug interactions are frequently seen when drugs metabolized by these enzymes are co-administered (Gonzalez et al., 2018; Snyder et al., 2012). The entire study was run with neither death nor replacing rabbits.

The introduction of therapeutic drug monitoring for CSA is extremely useful because of the wide inter- and intra-individual

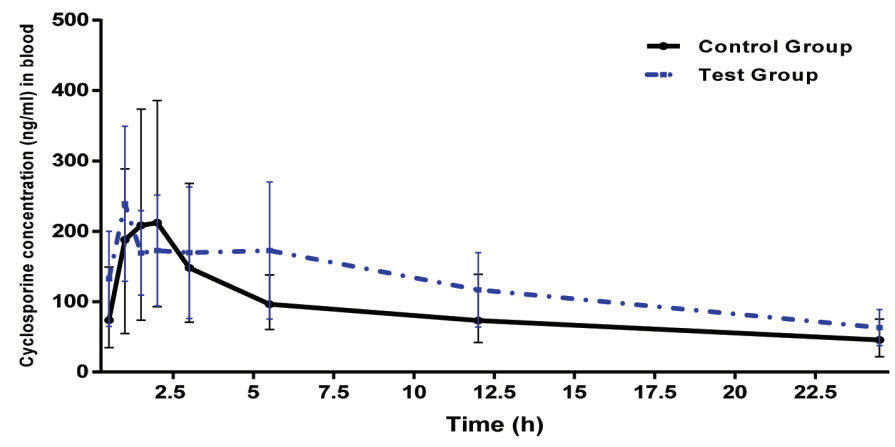

Figure 1. Mean blood concentrations-time profile of CSA in control and test groups of rabbits ( $n=6$ per group).

Table 1. Mean PK parameters of CSA in cotrol and test groups of rabbits ( $n=6$ per group).

\begin{tabular}{lccc}
\hline PK Parameters & $\begin{array}{c}\text { Control group* } \\
\text { (Mean } \pm \text { SD) }\end{array}$ & $\begin{array}{c}\text { Test group** } \\
\text { (Mean } \pm \text { SD) }\end{array}$ & p-value \\
\hline$C_{\max }(\mathrm{ng} / \mathrm{ml})$ & $244.67 \pm 115.87$ & $242.90 \pm 104.45$ & 0.968 \\
$t_{\max }($ hour$)$ & $1.75 \pm 0.76$ & $1.25 \pm 0.42$ & 0.314 \\
$t_{1 / 2}($ hour $)$ & $19.73 \pm 14.01$ & $17.40 \pm 5.54$ & 0.574 \\
$K_{\mathrm{e}}\left(\right.$ hour $\left.^{-1}\right)$ & $0.0519 \pm 0.03$ & $0.0439 \pm 0.01$ & 0.483 \\
$\mathrm{AUC}_{0-24}(\mathrm{ng} \cdot \mathrm{hour} / \mathrm{ml})$ & $2,057.8 \pm 778.6$ & $2,948.0 \pm 1,321.44$ & 0.127 \\
$\mathrm{AUC}_{0-\infty}(\mathrm{ng} \cdot \mathrm{hr} / \mathrm{mL})$ & $3,492.9 \pm 1,449.70$ & $4,605.4 \pm 2,205.20$ & 0.258 \\
\hline
\end{tabular}

variability of CSA PK parameters, narrow therapeutic window, and the severity of CSA adverse effects beside therapeutic failure consequences (Liu et al., 2016).

CSA is metabolized by CYP3A4 (Dai et al., 2004). Combined of CSA with CYP3A4 induction or inhibition can affect its plasma concentration. CSA blood concentration was decreased by $63 \%$ and the dose of CSA was elevated, when it was concomitantly administered with rifampicin (Perona et al., 2013). In another study, concomitantly using of St. John's wort, a CYP3A4 induction led to a significant decrease in CSA levels, resulting in organ transplant rejection and graft loss (Ruschitzka et al., 2000). In vivo PK interaction between CLN with CSA is poorly described in the literature. This investigation was performed in our study. According to our results regarding the PK parameters $\mathrm{AUC}_{0-24}$ and $\mathrm{AUC}_{0-\infty}$; there was statistical insignificance through $p$ values as illustrated in Table 1 . There was a clear similarity of our findings and López-Gil; who found insignificant alterations in CSA concentration/dose ratio in the patients undergoing bone marrow transplantation receiving fluconazole $100 \mathrm{mg} / \mathrm{dl}$ (LópezGil, 1993). In addition, ticagrelor and its active metabolite had statistically insignificant effect on CSA PK parameters (Teng et al., 2014).

\section{CONCLUSION}

In conclusion, it has been found that CLN does not affect the CSA PK parameters. Further confirmation of our findings is requiered before to be applied in humans by using larger number of animals to decrease interindividual variability of CSA PK parameters between both groups before these results can be applied in patient care.

\section{ACKNOWLEDGMENT}

The authors would like to thank all staffs in the Faculty of Pharmacy at Al-Azhar University of Gaza for their kind support and help. The authors would also like to thank Mr. Mohamed Abo-affash, the manager of Medical relief society (Gaza strip) for facilitating analyses in their laboratories.

\section{CONFLICTS OF INTEREST}

The authors declare that there are no conflict of interest.

\section{LIST OF ABBREVIATIONS}

Maximum blood concentration $\left(C_{\max }\right)$; The time to reach $C_{\max }\left(t_{\max }\right)$; ouThe elimination rate constant $\left(K_{\mathrm{e}}\right)$; The half-life $\left(t_{1 / 2}\right)$; The plasma concentration at time $t\left(C_{t}\right)$; Nanograms (ng); Miligrams (Mg); Kilogram (Kg); Mililiters (ml); Hour (h).

\section{REFERENCES}

Azzi JR, Sayegh MH, Mallat SG. Calcineurin inhibitors. 40 years later, can't live without. J Immunol, 2013; 191(12):5785-91.

Borel JF. History of the discovery of cyclosporin and of its early pharmacological development. Wien Klin Wochenschr, 2002; 114(12):433-7.

Campana C, Regazzi MB, Buggia I, Molinaro M. Clinically significant drug interactions with cyclosporine: an update. Clin Pharmacokinet, 1996; 30(2):141-79.

Dai Y, Iwanaga K, Lin YS, Hebert MF, Davis CL, Huang W, Kharasch ED, Thummel KE. In vitro metabolism of cyclosporine A by human kidney CYP3A5. Biochem Pharmacol, 2004; 68(9):1889-902.

Dhawan VK, Thadepalli H. Clindamycin. A review of fifteen years of experience. Clin Infect Dis, 1982; 4(6):1133-53. 
Estabrook RW. A passion for P450s (Remembrances of the early history of research on cytochrome p450). Drug Metab Dispos, 2003; 31(12):1461-73.

Faulds D, Goa KL, Cyclosporin BP. A review of its pharmacodynamic and pharmacokinetic properties and therapeutic use in immunoregulatory disorders. Drugs, 1993; 45(6):953-1040.

Gonzalez FJ, Coughtrie M, Tukey H. Drug Metabolism Brunton LL, Hilal-Dandan R, Knollmann BC (Eds). Goodman \& Gilman: the pharmacological basis of therapeutics, 13th Edition, McGraw-Hill, New York, pp 85-100, 2018.

Jouret F, Sneyers B, Goffin E, Castanares-Zapatero D. Interaction between tacrolimus and clindamycin. NDT Plus, 2010; 3(4):422-4.

Kelly P, Kahan B. Review: metabolism of immunosuppressant drugs. Curr Drug Metab, 2002; 3(3):275-87.

Kronbach T, Fischer V, Meyer UA. Cyclosporine metabolism in human liver: identification of a cytochrome P-450III gene family as the major cyclosporine-metabolizing enzyme explains interactions of cyclosporine with other drugs, Clin Pharmacol Ther, 1988; 43:630-5.

Larry BA. Applied clinical pharmacokinetics. 2ed edition. McGraw-Hill Medical, New York, NY, pp 649-681, 2008.

Liu Y, Luo X, Yang C, Yang T, Zhou J, Shi S. Impact of quercetin-induced changes in drug-metabolizing enzyme and transporter expression on the pharmacokinetics of cyclosporine in rats. Mol Med Rep, 2016; 14:3073-85.

López-Gil JA. Fluconazole-CsA interaction: a dose-dependent effect? Ann Pharmacother, 1993; 27(4):427-30.

Matsuda S, Koyasu S. Mechanisms of action of cyclosporine. Immunopharmacology, 2000; 47(2-3):119-25.

Parasuraman S, Raveendran R, Kesavan R. Blood sample collection in small laboratory animals. J Pharmacol Pharmacother, 2010; 1(2):87-93.

Perona A, Sáiz M, Tamajón L. Drug interactions with cyclosporine-rifampicin-clarithromycin in a kidney transplant recipient with mycobacterium malmoense. J Med Cases, North America, 2013; 4(4):227-229.
Rendic S, Di Carlo F. Human cytochrome P450 enzymes. A status report summarizing their reactions, substrates, inducers, and inhibitors. Drug Metab Rev, 1997; 29(1-2):413-580.

Ruschitzka F, Meier PJ, Turina M, Lüscher TF, Noll G. Acute heart transplant rejection due to Saint John's wort. Lancet, 2000; 355:548-49.

Şimşek A, Taner N, Macit Ç, Berk B, Mercanoğlu G. The importance of computerized drug interaction checker programs used in community pharmacies to avoid potential drug interactions: a preliminary study with clarithromycin. Istanbul Med J, 2019; (20):67-71.

Snyder, Ben D, Polasek T, Matthew PD. Drug interactions: principles and practice. Australian Prescriber, 2012; 35:85-1.

Teng R, Kujacic M, Hsia J. Pharmacokinetic interaction study of ticagrelor and cyclosporine in healthy volunteers. Clin Drug Investig, 2014; 34(8):529-36

Thurnheer R, Laube I, Speich R. Possible interaction between clindamycin and cyclosporine. Br Med J (Clinical Research Edition), 1999 319(7203):163.

Wynalda MA. In vitro metabolism of clindamycin in human liver and intestinal microsomes. Drug Metab Dispos, 2003; 31(7):878-87.

Yang X, Feng P, Yin Y, Bushley K, Spatafora JW, Wang C. Cyclosporine biosynthesis in tolypocladium inflatum benefits fungal adaptation to the environment. mBio, 2018; 9(5):01211-18.

Yasuda K, Ranade A, Venkataramanan R, Strom S, Chupka J, Ekins S, Bachmann K. A Comprehensive in vitro and in silico analysis of antibiotics that activate pregnane $\mathrm{X}$ receptor and induce CYP3A4 in liver and intestine. Drug Metab Dispos, 2008; 36(8):1689-97.

\section{How to cite this article:}

AbushammalaIM,ElGussein LA,ZomlotBE,Abushammalleh KF, Taha MM, Miqdad MM. Pharmacokinetic drug-drug interaction study between clindamycin and cyclosporin in rabbits. J Appl Pharm Sci, 2020; 10(02):108-111. 